\title{
Behavior of wood beam connection using staples subjected to in-plane moment
}

\author{
Farida Lenggani and Bambang Suryoatmono* \\ Department of Civil Engineering, Faculty of Engineering, Parahyangan Catholic University, Bandung, Indonesia
}

\begin{abstract}
It is very frequent that solid wood beams need to be connected one to another to obtain a longer beam. In this study, the behavior of solid wood beams connections using plywood sheets as connecting elements and staples as mechanical fasteners were studied experimentally. The experimental results were compared with elastic analyses. Both beam and plywood were made of meranti (shorea). The staple type was MAX 1022J. This study was conducted on two specimens. The first specimen had two rows of staples on the front and back sides of the specimen. Each row consisted of ten staples making a total of 40 staples. The second one had three rows of staples on the front and back sides of the specimen. Each row consisted of ten staples making a total of 60 staples. From the tests, it can be concluded that each material in the connection, namely wood beam, plywood, and staples, failed. Failure mode of the wood beam was in the form of crack and tear. Failure mode of the plywood was the damage of the plywood directly contacted with the crown of the staples. Failure modes of the staples were flexural yielding. The differences between connection strength obtained from tests and elastic analyses were $8.18 \%$ for the first specimen and $0.65 \%$ for the second specimen, with the test results were higher than the elastic analyses results. It can be concluded that elastic analysis is quite accurate and conservative to estimate the strength of this type of connection, provided that the lateral resistance of connection with a staple is known.
\end{abstract}

\section{Introduction}

The use of staples in wood connections has more advantage compared to other types of mechanical fasteners such as nails, screws, lag screws and bolts. It is because power-driven staples need shorter time to assembly compared to other types of mechanical fasteners. However, unlike other types of mechanical fastener, the design equations of wood connection using staples has not been established, even in the most recent code of wood structures [1]. The equations based on yield model theory for other types of mechanical fastener as seen in many codes have not yet been verified experimentally for staples [2].

There are many factors that affect the lateral strength of stapled wood connections, namely material density, staple dimensions, arrangement of staples, number of staples, and many others. The number of staples plays significant role in the performance of stapled wood connection [3]. In the moment resisting stapled wood connection, the load carrying capacity is affected significantly by material density and the number of staples [4]. Further research on in-plane moment resistances of Lshaped joints connected with two gusset plates stapled on one side of joint members in oriented strand board (OSB) showed that the ultimate moment resistances of joints connected with 12 staples were $43 \%$ higher than those with 8 staples [5].

In this paper, the behavior of wood beam connection using staples subjected to in-plane moment was studied experimentally. The beam was fixed ended and loaded with concentrated load at mid span. The connection was located at a cross section where the bending moment was zero and the shear force was nonzero. Therefore, the connection was subjected to in-plane moment induced by eccentric shear. Plywood was used as intermediate construction as suggested by Erdil et al [6]. Solid wood of meranti (shorea) was used as the beam, as seen in Fig. 1. The behavior of the connection, in terms of strength, failure mode, and ductility, was studied. The increasing number of staples is one of the key factors in increasing the connection strength [6]. To verify this, two configurations of connections were tested, namely a connection with a total of 20 staples to resist eccentric shear force $V$ and a connection with a total of 30 staples to resist eccentric shear force $V$.

Connection strength prediction using elastic analysis was also performed for comparison with the experimental results. The analysis is similar to the one commonly implemented in steel structures [7]. In steel structures, the

\footnotetext{
* Corresponding author: suryoatm@unpar.ac.id
} 
data needed in elastic analysis is the shear strength of the fastener assuming that bearing failure does not govern. In this paper, the necessary data for elastic analysis was the strength of the similar connection (plywood and solid wood) except that the staple was only one. This data was obtained experimentally.

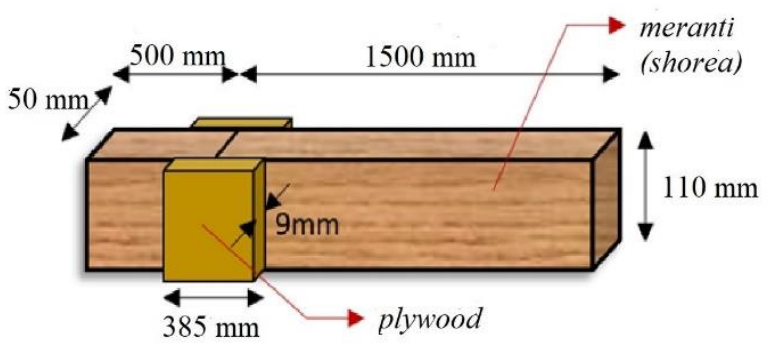

Fig. 1. Connection of solid wood beam using plywood and staples on both sides of the beam.

\section{Material and methods}

\subsection{Wood}

In this paper, there were two stapled connection specimens. The dimensions of the specimens are shown in Fig. 1. For each connection specimen, two solid wood beam made from meranti (shorea) with cross section of $50 \mathrm{~mm} \times 110 \mathrm{~mm}$ and length of $2000 \mathrm{~mm}$ were cut into two pieces, each of which had length of $500 \mathrm{~mm}$ and 1500 $\mathrm{mm}$. The difference between these two specimens were the number of staples. Specimen 1 and 2 had a total of 40 staples and 60 staples, respectively. The staples were distributed evenly on each side of the connections.

In addition, there were three identical specimens for establishing lateral strength of connection with a staple. The dimensions of the wood and plywood were shown in Fig. 2. The wood was also made from meranti.

All wood material was air dried until the equilibrium moisture content reached approximately $15 \%$. The specific gravity of meranti was measured according to ASTM D2395-17 [8]. The average specific gravity of the material was 0.46 .
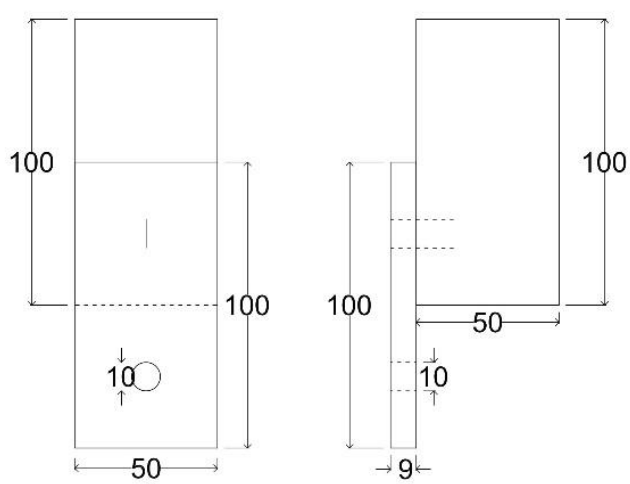

Fig. 2. Specimen dimensions for establishing the lateral strength of connection with a staple.

\subsection{Plywood}

Plywood used as part of the connection in this study had thickness of $9 \mathrm{~mm}$. It consisted of 5 plies of meranti veneer. The grain direction of the face veneer was parallel to the grain direction of the solid wood in both Fig. 1 and 2. Note that the load direction in Fig. 2 was vertical and the grain direction was horizontal so that the lateral strength of the staple obtained was perpendicular to the grain. This was the weakest lateral strength among other directions.

The dimensions of plywood for connection specimens were $385 \mathrm{~mm} \times 110 \mathrm{~mm}$ (Fig. 1). For connection specimen with a staple (Fig. 2), the plywood dimensions were $100 \mathrm{~mm}$ x $50 \mathrm{~mm}$. The circular hole in Fig. 2 was for attaching loads.

\subsection{Staples}

The type of two-legged staples used in this study was MAX 1022J. The lengths of crown and legs (see Fig. 3) were $10 \mathrm{~mm}$ and $22 \mathrm{~mm}$, respectively. Width and thickness of the staples were $1.2 \mathrm{~mm}$ and $0.6 \mathrm{~mm}$, respectively.

Pneumatic air nailer and air compressor were used in assembly process of staples in this study as seen in Fig. 4. By doing so, the assembly process was rapid and fairly accurate.

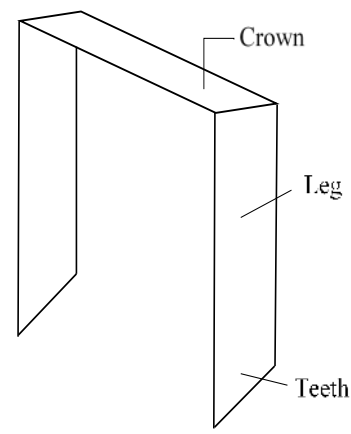

Fig. 3. Parts of a staple.

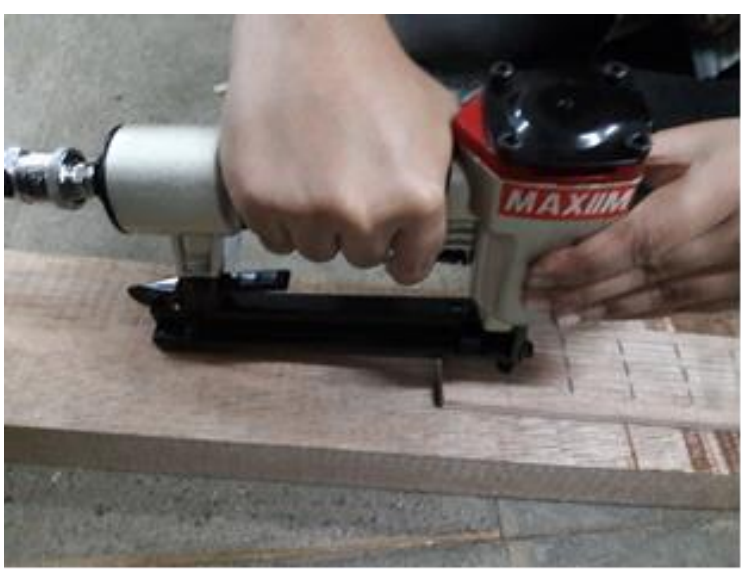

Fig. 4. Staples assembly process using pneumatic air nailer and air compressor in connection specimen. 


\subsection{Connection specimens}

The arrangement of staples for specimens 1 and 2 are shown in Fig. 5. The arrangement was used on both sides of the beam as seen in Fig. 1. From Fig. 1 and 5, it is clear that shear force $V$ of the beam at the location of the connection was carried by 20 staples for specimen 1 and 30 staples for specimen 2 . The eccentricity of the shear force to the centroid of the staples was $385 \mathrm{~mm} / 2=192.5$ $\mathrm{mm}$.

The beam span $L$ was $2000 \mathrm{~mm}$. Stapled connection was located at $L / 4=500 \mathrm{~mm}$ from one end. This was the location where the bending moment was zero and the shear force was $P / 2$ (see Fig. 6).

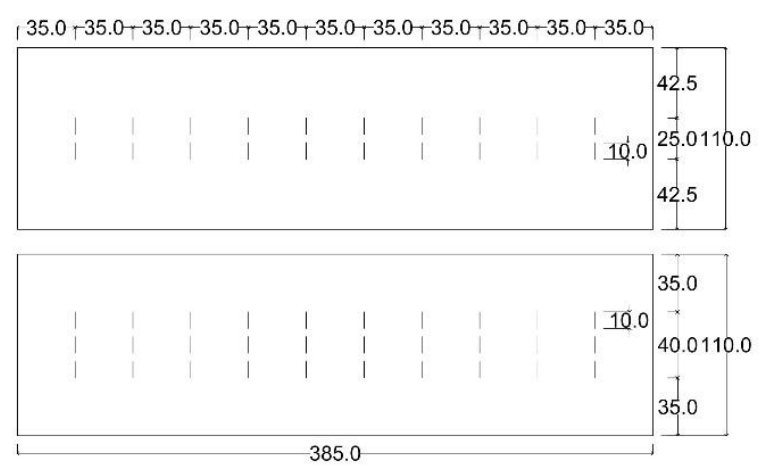

Fig. 5. Staples locations in connection specimens 1 (top) and 2 (bottom).

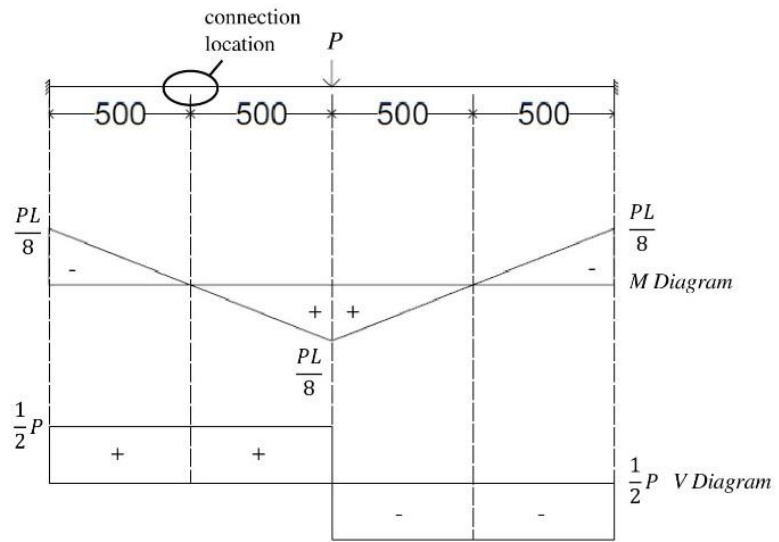

Fig. 6. Bending moment and shear diagrams of fixed ended beam subjected to concentrated load at mid span.

\subsection{Experimental setup}

\subsubsection{Testing lateral strength of connection with a staple}

Strength of connection with a staple is so small that a universal testing machine (UTM) cannot capture accurately. Therefore, in this study knob weights, wire, and ring as seen in Fig. 7 were used. To measure the displacement, linear variable displacement transducer (LVDT) was utilized. The knob weights were added one at a time and the displacement was recorded every time the knob weight was added. Three identical specimens as seen in Fig. 2 and Fig. 7 were tested and load versus displacement of each specimen was recorded.

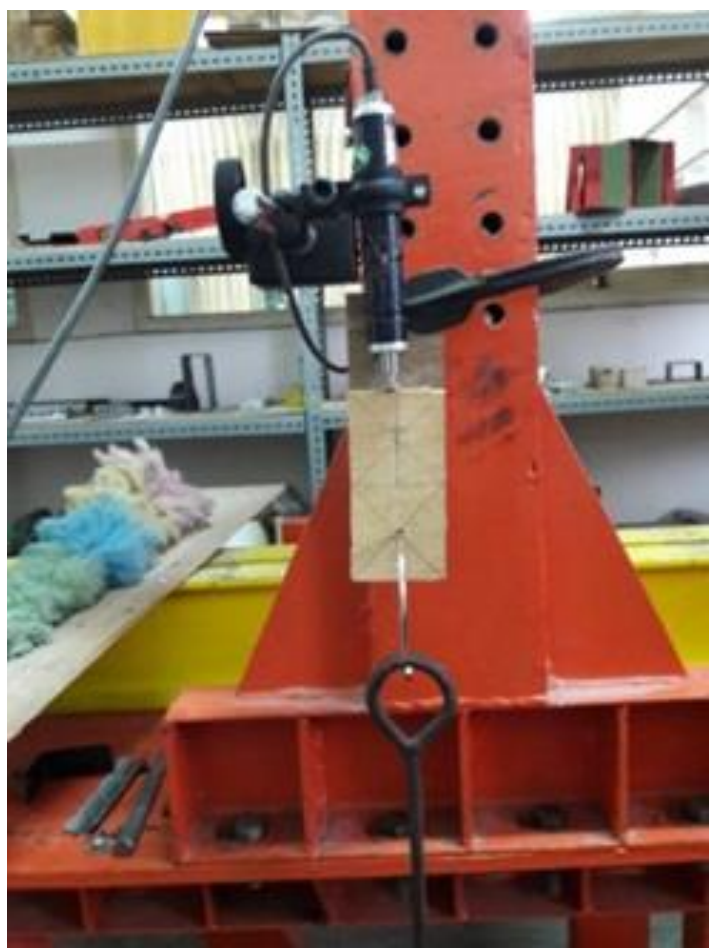

Fig. 7. Testing lateral strength of connection with a staple utilizing UTM and LVDT.

\subsubsection{Testing connection strength}

The tests of stapled connection strength were carried out in a universal testing machine as shown in Figure 8. The ends of each beam specimen were first clamped to the steel attachments that in turn were attached to the UTM as seen in Fig, 9. By clamping the beam specimen to the steel, the beam ends can be modelled as fixed. Vertical load was then applied to the specimen at mid span from the bottom. The loading was displacement controlled with a rate of $1 \mathrm{~mm}$ per minute of crosshead travel. The load was recorded directly into the computer attached to the UTM. LVDT was used to record displacement at mid span.

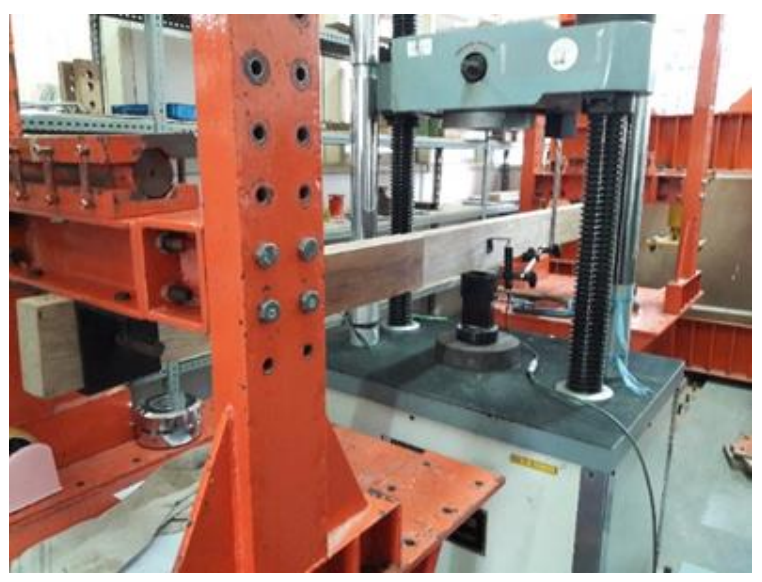

Fig. 8. Experimental setup of fixed ended loaded with concentrated load at mid span. 


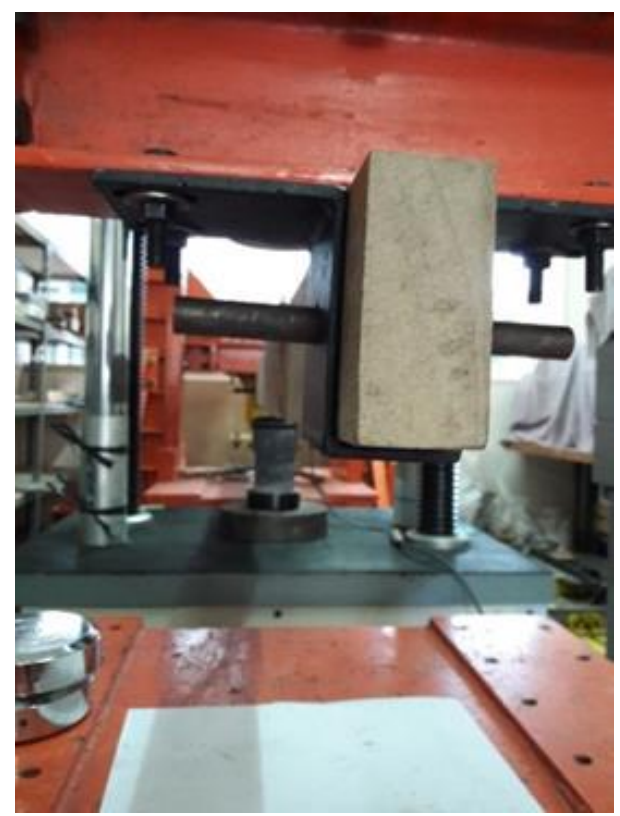

Fig. 9. Clamping beam end with rigid steel plates.

\subsection{Elastic analysis of the connection}

If a material behaves elastically, then superposition principle holds. Therefore, if a group of fastener is subjected to eccentric shear force $V$ as seen in Fig. 10, the analysis can be performed using superposition method. The method consists of analysis of direct shear $V$ at centroid of the fasteners and analysis of in-plane moment $M=V e$. The lateral (shear) force $R_{V}$ in the fastener due to direct shear $V$ in the same direction of the shear force is

$$
R_{V}=\frac{V}{n}
$$

where $n$ is the number of the fasteners. The direction of $R_{V}$ is the same as the direction of direct shear $V$. The lateral (shear) force $R_{M}$ in the fastener due to moment $M=V e$ only in the direction perpendicular to $r$ is

$$
R_{M}=\frac{M r}{\sum r^{2}}
$$

where $r$ is the distance from the fastener to the centroid of the fasteners and the summation sign sums up all $r^{2}$ of the fasteners. The resultant of $R_{M}$ and $R_{V}$ is the shear force in the fastener. By equating the largest fastener shear force and the strength of the connection with a staple obtained experimentally, the strength of the connection with staples under eccentric shear force $V$ can be determined.

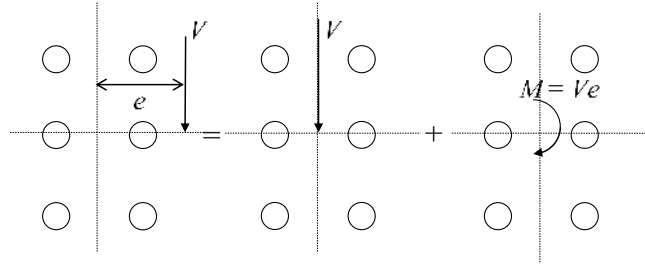

Fig. 10. Superposition method of elastic analysis of a connection.
From Eq. (1) it is clear that the shear force $R_{V}$ in each fastener due to direct shear $V$ is directly proportional to that the number of fasteners. On the other hand, the shear force due to the moment $R_{M}$ depends on the arrangement of the fastener (distance between fastener rows and distance between fasteners in a row) as indicated by the ratio $r / \sum r^{2}$ in Eq. (2). The resultant $R$ of the forces $R_{V}$ and $R_{M}$ depends not only to the absolute values of both forces but also to the angle between both forces.

As seen in Fig. 5, in this study the distance between fastener (staple) rows of specimens 1 and 2 are the same, i.e. $25 \mathrm{~mm} /$ The distance between staples in a row of specimens 1 and 2 are also the same, i.e. $35 \mathrm{~mm}$. Note that the number of staples in each row of specimens 1 and 2 are the same, i.e. ten staples. Therefore, the ratio between the maximum force in staple $R$ and the shear force in the staple due to direct shear $R_{V}$ for specimen 1 and 2 are 3.45 and 3.39 , respectively. These two values are nearly the same so that the further study of the effect of staple arrangement on the connection strength in this particular study is not necessary.

\section{Results and discussions}

\subsection{Lateral strength of connection with a staple}

In the preliminary stage of this study, it was found that the in-plane shear strength of plywood was $6.17 \mathrm{MPa}$. Therefore, the shear force capacity of plywood was $2 \mathrm{x}$ $6.17 \mathrm{MPa} \times 9 \mathrm{~mm} \times 110 \mathrm{~mm}=12.22 \mathrm{kN}$. The factor of 2 was used because there was plywood on each side of the beam. The shear force capacity is much higher than the connection strength so the plywood would not fail in the gross section, but rather failed in the section where the plywood was in contact with staples.

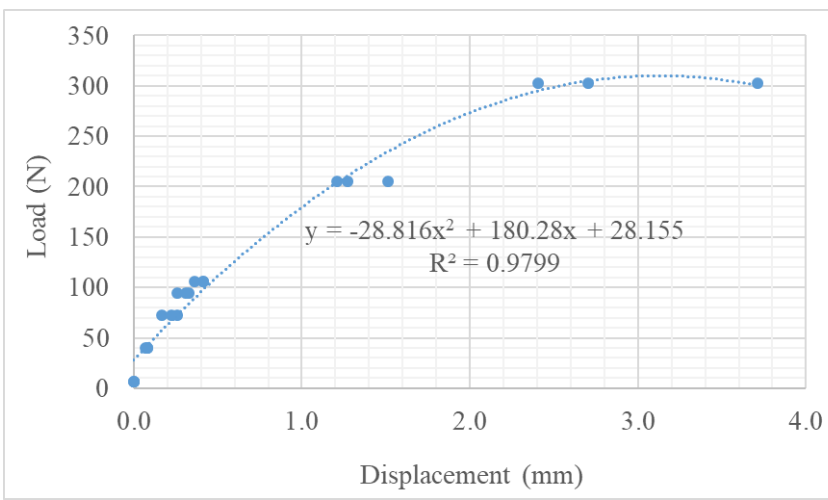

Fig. 11. Load - displacement regression curve and experimental data of three connection specimens. Each specimen had a staple.

Load versus displacement data obtained from the tests on three identical specimens are shown in Fig. 11. As seen in the figure, the strength of connection could not be determined directly. Therefore, regression analysis was carried out resulting quadratic relationship between load $(y)$ and displacement $(x)$ with coefficient of determination $R^{2}=0.9799$ as seen in the figure. By using the regression equation, the strength of connection with a staple (the 
peak of the curve) was $310.1 \mathrm{~N}$. This was needed in the elastic analysis of the beam connection with staples.

\subsection{Stapled connections behavior}

Load versus displacement curves of beam connection specimen 1 and specimen 2 are shown in Fig. 12 and 13, respectively. Note that the loads shown in both figures are the loads at mid span of the beam as recorded by UTM. Because shear force $V$ at connection location was half of the load $P$ (see Fig. 6) and there was connection on each side of the beam (see Fig. 1), therefore the strengths of connection specimen 1 and 2 were $3912.21 \mathrm{~N} / 4=978 \mathrm{~N}$ and $5520.88 \mathrm{~N} / 4=1380 \mathrm{~N}$, respectively. Increasing the number of staples by 1.5 from specimen 1 to specimen 2 resulted in increase of connection strength by $1380 / 978=$ 1.41. This means the number of staples in the connection was nearly proportional to the strength of the connection. The same conclusion was drawn by Erdil et al. [6].

Elastic analyses of both specimen 1 and 2 were conducted using the strength of connection with a staple of $310.1 \mathrm{~N}$ obtained experimentally as the basis. The results are shown in Table 1 . It is seen that the beam stapled connection strengths obtained from elastic analyses were only slightly lower than the experimental ones.

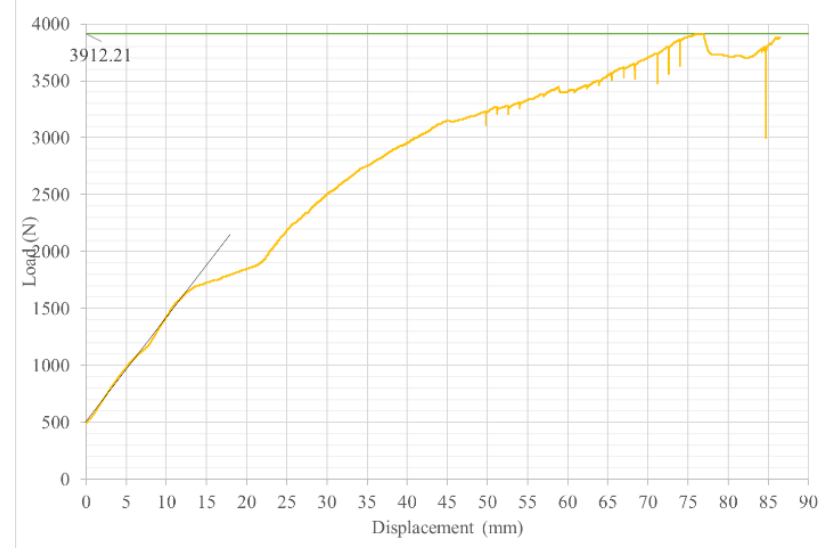

Fig. 12. Load versus displacement curve of specimen 1.

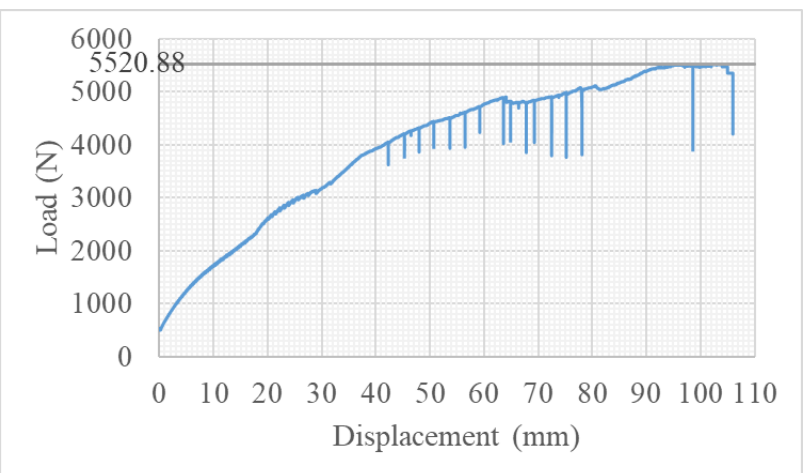

Fig. 13. Load versus displacement curve of specimen 2.

Ductility is defined as the ability of material, connection, cross section, or structure to undergo significant inelastic deformation without failure. By observing load - displacement curves in Fig. 12 and 13, it is clear that the ductility of both specimens were quite high. This is the characteristic of wood connection using mechanical fasteners.

Table 1. Lateral strengths of stapled connection specimens.

\begin{tabular}{|c|c|c|c|}
\hline Specimen & $\begin{array}{c}\text { Strength } \\
\text { (elastic } \\
\text { analysis) } \\
\text { (N) }\end{array}$ & $\begin{array}{c}\text { Strength } \\
\text { (experiment) } \\
\text { (N) }\end{array}$ & $\begin{array}{c}\text { Difference } \\
(\mathbf{\%})\end{array}$ \\
\hline 1 & 898 & 978 & -8.18 \\
\hline 2 & 1371 & 1380 & -0.65 \\
\hline
\end{tabular}

Fig.14 shows typical failure of the stapled connection. Clearly failure happened to all parts in the connection. Failure mode of the plywood was the damage of the plywood directly contacted with the crown of the staples. Failure modes of the staples were in the form of flexural yielding. Shear failure did not happen to the staples. The connected beam members failed in the form of crack and tear. Of course, the failures did not happen all at once as indicated by degrading stiffness in the load displacement curves.

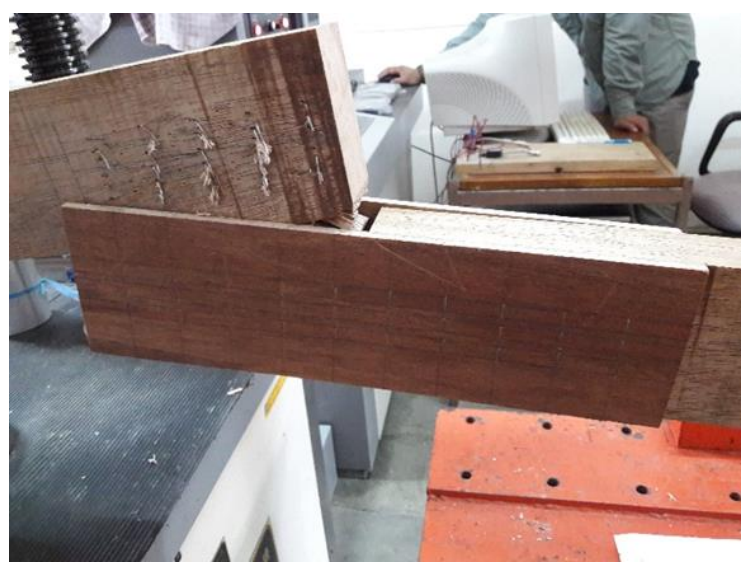

Fig. 14. Failure of the connection.

\section{Conclusions}

The behavior of wood beam connection using staples subjected to in-plane moment have been studied experimentally. It can be concluded that the use of staples increases the ductility of the connection. Furthermore, the number of staples has significant role to the strength of the connection. The number of staples in the connection is nearly proportional to the strength of the connection.

Elastic analysis of the connection is proven to be conservative and quite accurate to predict the strength of wood beam connection using staples subjected to in-plane moment. The strength of similar connection using a staple has to be determined experimentally in order to use elastic analysis.

Further researches are suggested to study the effect of staple arrangement (distance between staple rows and 
distance between staples), staple dimensions (crown, leg, and teeth lengths), specific gravity of wood, and dimensions of connected elements, on the behavior of wood beam connection using staples subjected to in-plane moment.

The authors wish to acknowledge the Department of Civil Engineering, Faculty of Engineering, Parahyangan Catholic University for the facility in Structural Laboratory and the financial support.

\section{References}

1. AWC, National Design Specification for Wood Construction 2015 Edition (Leesburg, 2015)

2. FPL, Wood handbook - Wood as an engineering material, Gen Tech Rep FPL-GTR-190. USDA For Serv Forest Products Laboratory (Madison, WI. 2010)

3. S. Demirel, J. Zhang, Wood and Fiber Sci. 46, 280290 (2014)

4. S. Demirel, J. Zhang, Wood and Fiber Sci. 46, 356367 (2014)

5. S. Demirel, X. Yu, O. Tor, J. Zhang, Wood and Fiber Sci. 48, 202-210 (2016)

6. Y. Z. Erdil, J. Zhang, C. A. Eckelman, Forest Products J. 53, 70-75 (2003)

7. W.T. Segui, Steel Design 6th Ed, 494-508 (CL Engr, Boston, MA, 2017)

8. ASTM D2395-17, Standard Test Methods for Density and Specific Gravity (Relative Density) of Wood and Wood-Based Materials (West Conshohocken, PA, 2017) 